\title{
Perceptual analysis of THERMAL-LUMINAL comfort in areas shaded by vegetation in design education centers
}

\author{
Blanca-Giménez, V. *; Gurrea-Ysasi, G.; Rodríguez-Burruezo, A.; Fita, I. \\ Instituto COMAV, Edif. 8E, Acceso J, Ciudad Politécnica de la Innovación. Universitat Politècnica \\ de València. Camino de Vera s/n C.P. 46022, Valencia, Spain \\ *corresponding autor: vblanca@csa.upv.es
}

\begin{abstract}
The search for comfort in users is a priority objective in technical schools focused on spaces design. The use of spaces can be for residential, commercial or entertainment activities. It is a common mistake to consider that comfort is achieved exclusively through the analysis of the interior space, since it is also necessary to consider the relationship between the space and the surrounding environment, because it is affected by environmental variables such as radiation, wind, humidity, noise, etc. The change of these variables throughout the day influences the interior conditions of the spaces and in general, is needed to incorporate artificial systems to compensate the external climatological conditions (thermal machines, light sources, etc.).
\end{abstract}

Grade students, in design schools acquire, throughout the curriculum, knowledge in relation to the limits of comfort required for interior spaces. In the last academic year of the degree in Architecture, students have sufficient capacity to be able to detect the fluctuations that occur in the variables of the external environment by measuring temperature and humidity with DATALOGGER, equipment capable of recording data over time or in relation to the location using its own sensors or externally connected, as well as the value of the light level with LUXOMETERS, which are instruments that measure the real and not subjective illuminance of an environment.

On the other hand, students are also able to evaluate the quality of the indoor environment, detecting whether or not there is a difference with the outdoor environment and assessing, for each orientation, the need for protection against radiation, (possible incorporation of tree mass, etc.).

The protocol for developing the work proposal is established with measurements at the beginning of the course (winter period), later in spring and at the end of the course (beginning of summer). For each space analyzed 
Perceptual analysis of THERMAL-LUMINAL comfort in areas shaded by vegetation in design education centers.

(indoor and outdoor), measurements are carried out three times a day (early in the morning, at noon and in the evening).

With the data obtained in different moments of the day and stationary situations, students must be able to select the most suitable protection devices for the building under analysis (vegetation, canopies, etc.)..

Keywords: Grade studies, practical session, thermal-luminal design

\section{Introduction}

The perception of environmental problems increasingly serious and dangerous, has caused, an awareness about the needed of finding effective solutions.

The human environment is not only natural, constituted by water, air, and climate, temperature, soil, relief, solar and cosmic radiation (which are part of the habitat of the human species), but also the social environment is a key factor. United Nations (1) agreed on an Action Plan, to deal with this adverse situation, both for the monitoring of environmental problems and for their solution, being education one of the the indinspensable supports considered.

Later, contributions corresponding to education were designed, establishing function, objectives, guiding principles, addressees, contents and methods of educational innovation, also called environmental education (2).

Environmental design programs in education correspond to a multidisciplinarity in their own right providing a solid foundation in design education for students who choose careers and / or postgraduate studies. Degrees in fundamentals of Architecture, Urbanism, Interior Design and Landscape Architecture, Environmental Sciences, etc.. are included.

In general, programs agree in training experts on topics related to the integration of new technologies, concepts and developments in the various fields of environmental technology. While in a degree the goal is to give a more general education, in master and postgraduate courses it is intended to provide specialization in different areas of technical knowledge related to environmental field, with a marked interdisciplinary nature.

The analysis that is carried out is dual. On one hand, everything that has to do inside the building is analyzed. On the other hand, the exterior space, of a public nature, responding to the urban environment. 
The objectives of programs are focused, first of all, on reducing the impacts produced by buildings and their urban environment, acting in the reduction of energy consumption, materials and water, as well as discharges, emissions, noise, waste, occupation of soil, modification of ecosystems, fire, etc. from a global concept of sustainability: environmental, economic and social. Secondly, on easing the development of new criteria and design techniques in order to design buildings with technologies responding to actions received and current regulatory requirements, together with the optimized management of building process. New methods of designing steel, wood and mixed structures, as well as digital tools that favor resources saving, transfer and integration of new technologies to the productive sector. New materials and construction systems for enclosures buildings design, exterior and interior, both for installations and for coatings.

The training process in the context of the university is oriented to instruction, education and development of future professionals, responding to the society demands, for which the accumulated culture is systematized and recreated in a planned and organized manner (Cantú Hinojosa, 2004 and 2010).

The current university pedagogy aspires to the formation of professionals who combine knowledge, values and skills with a comprehensive general culture; in this sense Marín (2007), defines as a fundamental objective of the training process, training professionals able to respond to social demands, with creativity and independence.

The goal of this article is to characterize from a specific context the place occupied by the perceptual analysis of thermal-light comfort in areas shaded by vegetation in design schools, by students. For this purpose, different specific purposes allowing compliance are addressed:

Characterization of environmental training, analysis the environmental education of students in design schools, justification of sustainability education as a current trend, and exposition of essential aspects about the diagnosis of this type of training, in a classroom model that allows the development of eminently practical classes with great teacher-student interaction. (Fig. 1) 


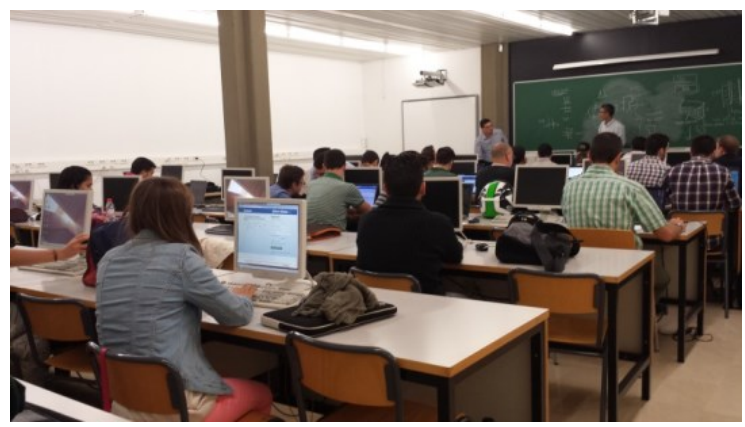

Fig.1 Classroom design

\section{Characterization of the formative process in the perceptual analysis of the luminous thermal comfort of the student of the design school}

Disciplinary integration is the form of cooperation between subjects in the treatment of a common scientific or professional problem to find its solution. It means articulation and integration of knowledge, which implies new points of view, methods and more general knowledge.

From this conception, the disciplinary integration is not reduced to the knowledge system; it also includes a system of habits, skills and abilities that must be achieved as a result of the teaching-educational process. It establishes the formation of the systems of knowledge, habits and skills that serve as basis for all the significant social qualities in a way that allows the student to form a generalized system of knowledge integrated in his conception of the world. (Gatell, A, 2014)

The disciplinary integration is also assumed as a teaching-learning strategy that prepares students to make content transfers allowing them to solve problems they will face in their professional practice.

In the case of Design Schools, architectural and Urban Project is defined as the main axis of studies. It is taught in every course of the degree and it is linked to the rest of the disciplines (thus, the facilities, allow the project to gain entity in thermal, light, electrical, hydraulic, etc.). It is also given in master, and its objective is to develop the theoretical knowledge and practical skills necessary for the realization of architecture and urban planning projects, integrating the knowledge acquired in the rest of the degree in the conception and realization of these projects. 


\section{Meaning of the design process in the student's training}

In student's education, the knowledge and design process is fundamental for his future professional performance. Through them, competences involving imagining, devising and designing projects, are acquired. The design process is also a way of knowledge, imagination, reflection and anticipation. It allows the meaning and transformation of reality, it produces real works, but it also seeks to get the user excited about the values and formal qualities that these works provide, through spatial experiences and use. This process develops reflective, predictive, creative and innovative skills and represents "learning by learning" and thus unleashes a "knowledge making increasingly predictive and strategic" becoming an extraordinarily effective way of learning in order to model, configure and transform the world .

(Pérez, E.,2004), defines the design method not as an isolated or final result, but as a process, an entire sequence of steps in stages and phases leading to solving the problem (the needs).

The fact that, among the indicators of quality of life in the cities, environmental ones are included increasingly in a greater proportion, represents an additional reason that justifies the need to include these subjects in the programs of the design subjects. .

Particularly, by visual and thermal perception we understand the interpretation or discrimination of visual and thermal external stimulu related to the prior knowledge and the emotional state of the individual ".

\section{Diagnosis on perceptual analysis of thermal-light comfort}

Methodology used and analysis of results.

After the completion of the generic project carried out by students in the first two courses of Design Studies, upon reaching the third course, environmental technologies from other subjects are incorporated in order to enrich the project. In this stage, field visits are made allowing the student to experience what he is projecting (fig.2) 
Perceptual analysis of THERMAL-LUMINAL comfort in areas shaded by vegetation in design education centers.

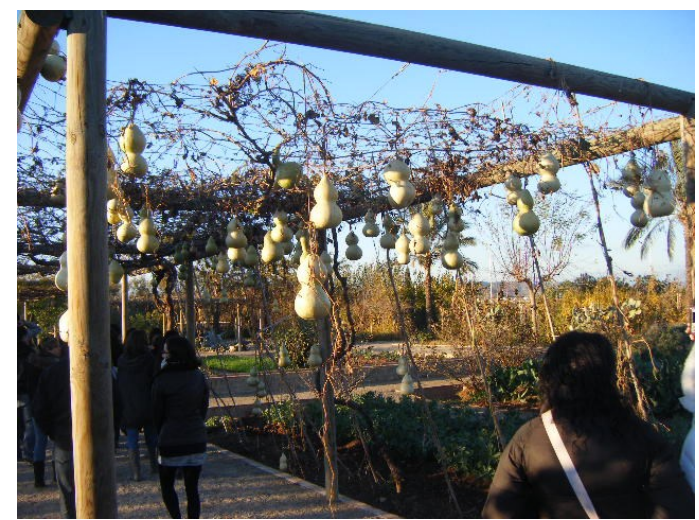

Fig.2 Visit to the Environmental Education Center of the C.V.

Questionnaires are prepared on the specific topic and are completed during the visit.

Temperature, humidity and luminosity measurements are also carried out with dataloggers, luxometers, etc. in order to intereact with the instrumentation and technology (fig.3)

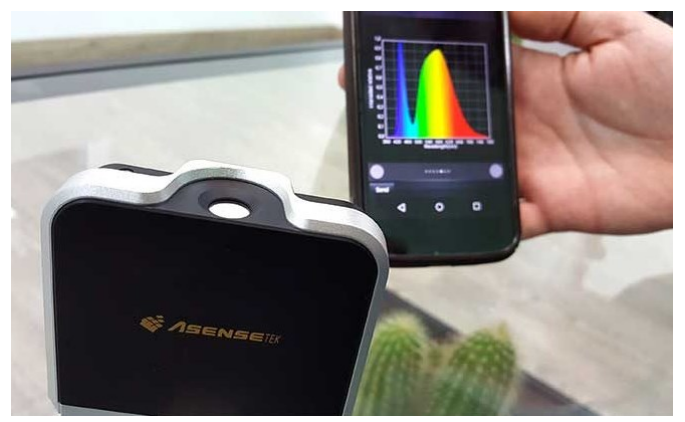

Fig.3 Light meter

Measurements are carried out in different environments: interior, exterior without solar protection, exterior with protection of cast shadows, exterior with protection of vegetation cover, etc., planning different scenarios to analyze the response of user in different environments, specifically the thermal and the light one.

Analysis, including control of environmental variables as the main response of the project, is fundamental, incorporating, if necessary, the use of artificial systems.

Although the methodology used continues to be what we call "traditional", a rapid increase in Reverse Teaching is observed, allowing the student to visualize audiovisual Polimedias at home becoming the class hours more practical. 
Students are invited to participate in project competitions where sustainability, technological innovation and low energy consumption are rewarded, obtaining very interesting results due to their high quality, such as the one shown in figure 4.

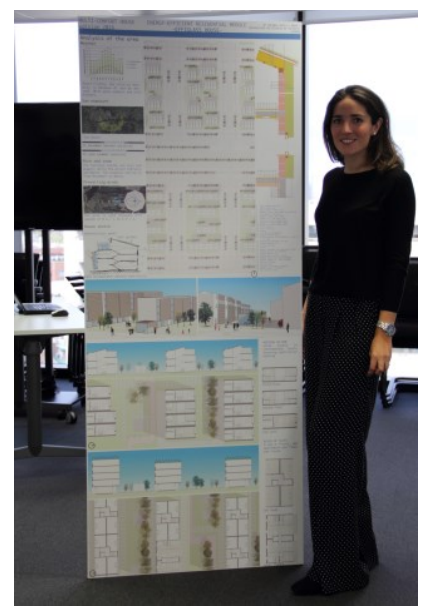

Fig.4 Project representation environmental

Those who decide to carry out these extracurricular activities expand the contact with the university, and provide us with valuable information.

\section{Conclusions}

The analysis made highlights the use of environmental technology in design centers, constituting a topic of vital importance for the training of the future student.

Transversality is necessary in the different disciplines that make up the degrees, as well as in extracurricular activities.

There is an improvement and greater use of this process by the student, although it is clear that not all subjects contribute to the potential of the project.

Current regulations, together with the modification of R.D. 314 may 17th, 2006, of the technical code of the building, in its draft royal decree, highlights the importance and need for awareness to work under the slogan "almost zero energy consumption building", which can not be achieved without knowledge of environmental matters.

Graduates, in their professional practice, also recognize the need for environmental training. 
Perceptual analysis of THERMAL-LUMINAL comfort in areas shaded by vegetation in design education centers.

\section{References}

Alonso Gatell, Aymeé y otros (2014). Contexto. Revista de la Facultad de Arquitectura de la Universidad Autónoma de Nuevo León nº 8 pag.69-90

Cantú Hinojosa, Irma Laura (2010). "Nuevos desafíos en la formación de arquitectos a partir del impacto de la sostenibilidad en la arquitectura". Entelequia: Revista interdisciplinar, $\mathrm{N}^{\mathrm{o}} 12$, pp. 273-287.

Marín, Carmen (2007). Estrategia educativa para la educación en valores del estudiante universitario desde la interacción tutor - estudiante en condiciones de universalización. Tesis doctoral. Camagüey: Universidad de Camagüey.

Naciones Unidas (1972). Conferencia sobre el ambiente humano, convocada por las Naciones Unidas.

Pérez, Elio (2004). "El método y la metodología de diseño", XII Encuentro de Arquitectura,Urbanismo y Diseño México. Cuba. Camagüey, Cuba: Universidad de Camagüey.

Unesco (1977). Conferencia intergubernamental sobre educación ambiental, convocada por la Unesco. Tbilisis, URSS 